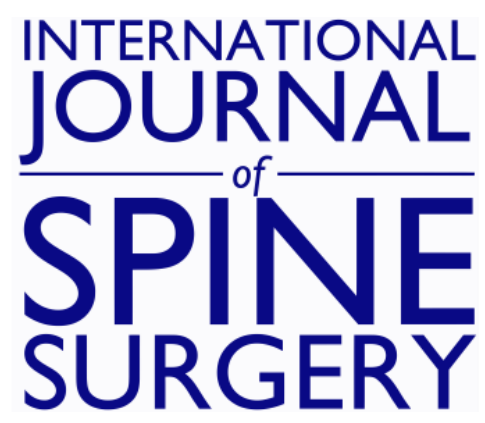

\title{
Anterior Lumbar Interbody Fusion With Cement Augmentation Without Posterior Fixation to Treat Isthmic Spondylolisthesis in an Osteopenic Patient--A Surgical Technique
}

MATHEW CYRIAC, JUSTIN KYHOS, UCHECHI IWEALA, DANNY LEE, MATTHEW MANTELL, WARREN YU and JOSEPH R. O'BRIEN

Int J Spine Surg 2018, 12 (3) 322-327

doi: https://doi.org/10.14444/5037

http://ijssurgery.com/content/12/3/322

This information is current as of April 26, 2023.

Email Alerts Receive free email-alerts when new articles cite this article. Sign up at: http://ijssurgery.com/alerts 


\title{
Anterior Lumbar Interbody Fusion With Cement Augmentation Without Posterior Fixation to Treat Isthmic Spondylolisthesis in an Osteopenic Patient-A Surgical Technique
}

\author{
MATHEW CYRIAC, MD, MBA, ${ }^{1}$ JUSTIN KYHOS, $\mathrm{MD},{ }^{2}$ UCHECHI IWEALA, MD, MBA, ${ }^{3}$ DANNY LEE, BS, ${ }^{3}$ \\ MATTHEW MANTELL, MD, ${ }^{3}$ WARREN YU, MD, ${ }^{3}$ JOSEPH R. O'BRIEN, MD, MPH ${ }^{4}$ \\ ${ }^{I}$ Tulane University, New Orleans, Louisiana, ${ }^{2}$ Northwestern University, Chicago, Illinois, ${ }^{3}$ George Washington University, Washington DC, ${ }^{4}$ Washington Spine \\ and Scoliosis Clinic, OrthoBethesda, Bethesda, Maryland
}

\begin{abstract}
Background: Anterior lumbar interbody fusion (ALIF) has been well established as an effective surgical intervention for chronic back pain due to osteoporotic vertebral collapse. Historically, ALIF has consisted of an anterior approach to disc height restoration with a subsequent posterior pedicle screw fixation. Although the applications of cement augmentation with posterior fixation have been previously reported, treatment of patients with both isthmic spondylolisthesis and decreased bone mineral density using a stand-alone ALIF is controversial because of concerns for decreased fusion rates and increased subsidence risk, respectively. We report a case of stand-alone ALIF used to treat a low-grade isthmic spondylolisthesis in the setting of idiopathic thoraco-lumbar scoliosis in a patient with secondary degenerative changes and discuss the benefits of this surgical technique in a patient with several comorbidities.

Methods: An osteopenic 66-year-old woman with multiple medical comorbidities and 2 years of left radicular leg pain was found to have a Myerding grade I isthmic spondylolisthesis in the setting of idiopathic thoraco-lumbar scoliosis with secondary changes. The patient underwent an L5-S1 stand-alone ALIF with anterior cement augmentation without posterior pedicle screw fixation.

Results: The patient experienced immediate relief of radicular leg pain postoperatively and had an uneventful course. At 2 years follow-up, she remained symptom free, and radiographs showed excellent fusion and maintenance of intervertebral disc height.

Conclusions: The use of stand-alone ALIF with anterior cement augmentation of the vertebral bodies is a surgical technique that could produce excellent improvement in patients with low-grade isthmic spondylolisthesis in the setting of osteopenia. The use of the all-anterior approach in similar patients with multiple medical comorbidities can also be a useful technique, as it decreases associated morbidity of surgery and complication risks associated with prolonged operative times.
\end{abstract}

Lumbar Spine

Keywords: anterior lumbar interbody fusion, osteopenia, osteoporosis, anterior cement augmentation, isthmic spondylolisthesis

\section{INTRODUCTION}

Isthmic spondylolisthesis is the result of a defect in the pars interarticularis that leads to the forward slippage of a vertebra, causing foraminal compression of nerve roots. Many surgical options exist to correct spinal pathology, including anterior lumbar interbody fusion (ALIF), posterior lumbar interbody fusion, transforaminal lumbar interbody fusion, posterolateral fusion, and circumferential fixation, with numerous case-specific factors affect- ing the surgeon's preferred approach. ${ }^{1}$ Among the available techniques, however, there remains no consensus for optimal surgical management. ${ }^{2,3}$ Compared with other fixation techniques, ALIF provides improved access to the anterior spinal column, allowing for better sagittal and coronal correction of the index segment deformity. This procedure relies upon restoration of disc height to provide for direct and indirect decompression of the neural elements. ${ }^{4}$ It also allows for increased surface area for fusion that in general results in less implant 
subsidence, provided there is adequate disc removal, endplate preparation, and removal of the posterior longitudinal ligament to allow for distraction.

Osteoporosis is a common disorder caused by a perturbation in the regulatory mechanisms that govern cellular bone formation and resorption. The end result is the creation of bone that has less structural support and is comparatively weaker than non-osteoporotic bone. ${ }^{5}$ For this reason, use of stand-alone anterior spinal fusion procedures in patients with severe osteoporosis remains controversial because of increased risk of endplate or vertebral body fracture. Augments such as polymethyl methacrylate (PMMA), colloquially known as bone cement, act as a mechanical interlock between the irregular bone surface and the implant, thereby improving strength of the construct and reducing the incidence of subsidence. ${ }^{6}$ Prior studies have described ALIF with cement augmentation and supplemental posterior fixation for these osteoporotic patients, but the two-site approach when using traditional techniques to place posterior instrumentation has been associated with longer operative time, increased blood loss, and increased complication rates. $^{7-9}$ Specifically with percutaneous pedicle screw placement, there is greater radiation exposure and violation of cranial facet joints, which can lead to altered biomechanics at the adjacent level. ${ }^{10}$ Other studies have shown pseudoarthrosis rates from $0 \%$ to $49 \%$ in ALIFs without supplemental posterior fixation. ${ }^{11,12}$ If sufficient fixation can be provided by a single surgery, then the additional risks associated with combined anterior and posterior approaches can be avoided. ${ }^{13}$ In this report, we describe an L5-S1 ALIF with anterior cement augmentation without supplemental posterior fixation in an osteopenic patient for Myerding grade I isthmic spondylolisthesis in the setting of thoraco-lumbar scoliosis with secondary degenerative changes.

\section{CASE REPORT}

\section{History, Physical Exam, and Diagnostic Workup}

A 66-year-old woman with chronic persistent left leg radicular pain resistant to conservative treatment presented in June 2013. Neurological examination findings were unremarkable; the patient had full sensation and strength in the lower extremity. She required use of a significant amount of narcotics to control her pain. Plain radiographs and magnetic

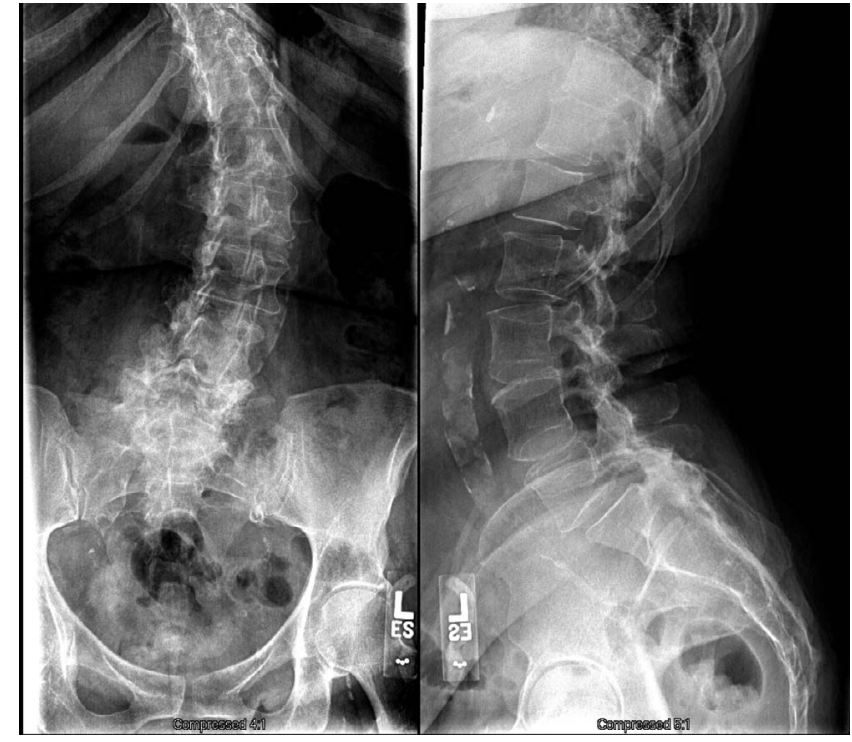

Figure 1. Preoperative anterior posterior (left) and lateral (right) lumbar radiographs showing spondylosis, lumbar scoliosis curve, and a grade I L5-S1 anterolisthesis.

resonance imaging showed a $41^{\circ}$ left lumbar scoliosis curve with a grade I L5-S1 anterolisthesis with bilateral pars defects (Figure 1). Imaging also showed lumbosacral spondylosis most severe at L5S1, including advanced facet arthropathy, and disc osteophyte complexes resulting in foraminal stenosis and impingement of the left L5 and S1 nerve roots. The dual-energy x-ray absorptiometry scan showed osteopenia with a T-score of -2.1 . The use of posterior instrumentation was deemed undesirable because of her attendant scoliosis and lateral listhesis at L4-5.

\section{Technique for ALIF With Anterior Cement Augmentation Without Supplemental Posterior Fixation}

An anterior, paramedian, left-sided, retroperitoneal approach localized over L5-S1was performed. C-arm fluoroscopy was used to localize the L5-S1 level. An L5-S1 total discectomy was performed with removal of the cartilaginous endplates and posterior annulus. A medium-footprint $13-\mathrm{mm}, 15^{\circ}$ interbody cage (Globus, Aubudon, Pennsylvania) packed with recombinant human bone morphogenic protein-2 (Medtronic, Minneapolis, Minnesota) and collagen/ceramic strip (Globus, Aubudon, Pennsylvania) was tapped into the disc space with interference fit observed. Integral fixation of the interbody cage was achieved with $25-\mathrm{mm}$ screws caudal and cephalad. Vertebroplasty was then performed by placing 2 cannulas $10 \mathrm{~mm}$ deep into 


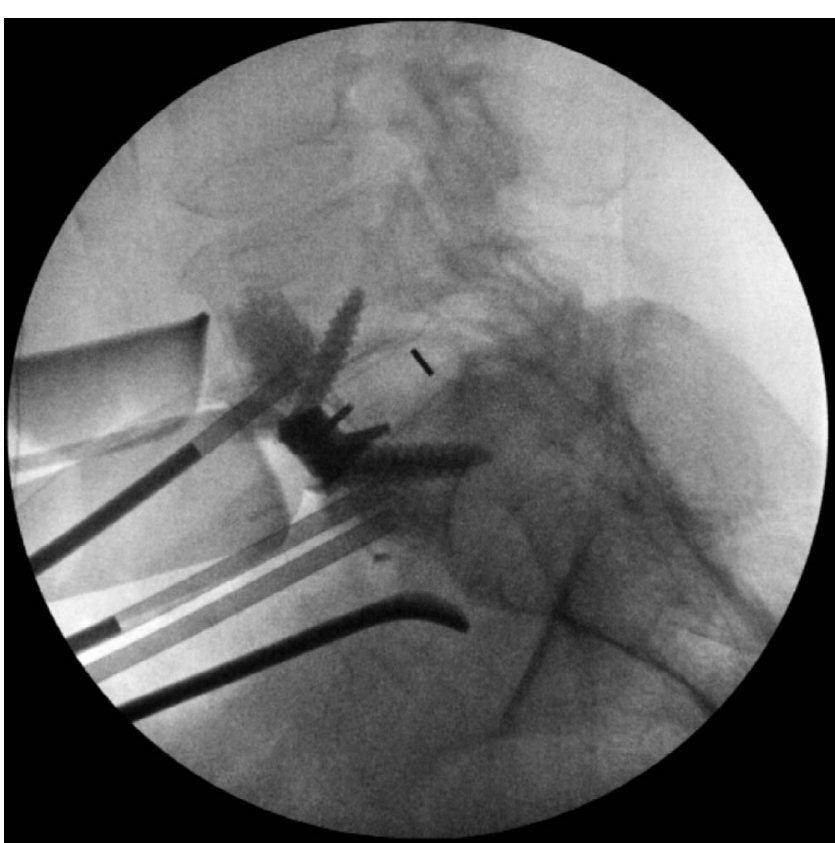

Figure 2. Intraoperative final C-arm fluoroscopy image with cannulas in place after polymethyl methacrylate augmentation of L5 and S1 vertebral bodies.

S1 and 1 cannula into L5. Three milliliters of PMMA was injected into both the S1 and L5 vertebral bodies with the use of neuromonitoring and $\mathrm{C}$-arm fluoroscopy throughout. Final confirmation under C-arm flouroscopy (Figure 2) showed appropriate placement of PMMA. A standard wound closure was performed.

\section{Postoperative Course}

Postoperative day 1, the patient experienced immediate relief of preoperative left leg radicular pain and was completely neurologically intact. She was discharged home on postoperative day 3 on postoperative pain medication and weekly alendronate for 8 weeks to decrease subsidence. ${ }^{14}$ At 2 years follow-up, she was symptom free and no longer required use of any narcotic pain medication. Lumbar radiographs showed stable fusion at L5S1 without subsidence, hardware loosening, or vertebral body height loss (Figure 3).

\section{DISCUSSION}

Operative treatment of isthmic spondylolisthesis lacks a definitive consensus, with many fusion techniques having been used in these patients, including ALIF, posterior lumbar interbody fusion, transforaminal lumbar interbody fusion, posterolateral fusion, and circumferential fusion. Significant research has been done to determine the

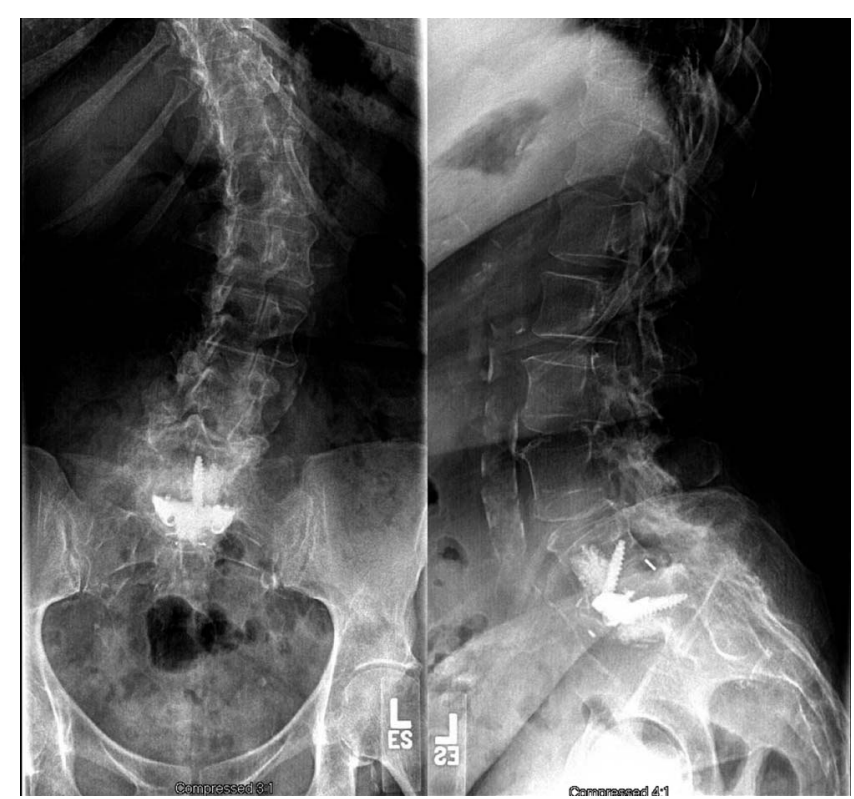

Figure 3. Anterior posterior (left) and lateral (right) lumbar radiographs at 2 years showing excellent interbody fusion without any hardware loosening or loss of vertebral body height.

superiority of each technique with still no consensus. ${ }^{2,3}$ Circumferential fusion in the form of ALIF with posterolateral fusion produces the highest fusion rates but also results in the most complications. ${ }^{3,15}$ Strube et al ${ }^{16}$ compared the clinical results of patients who underwent fusion with stand-alone ALIF and those of patients receiving ALIF with pedicle screw fixation and found that pain assessed through both visual analog scales and Oswestry Low Back Pain Disability Index improved more significantly among patients treated with standalone ALIF, which questions the clinical relevance of radiographic fusion in patients' postoperative functional improvement. Long-term clinical followup of patients treated with ALIF for isthmic spondylolisthesis confirms the satisfactory results at 10 years after surgery. ${ }^{17,18}$

While there are many surgical options for the treatment of spondylolisthesis, comorbid osteoporosis or osteopenia complicates the management of these patients. ${ }^{12,19}$ With both osteoporosis and osteopenia, the decrease in bone mineral density correlates to reduced screw pullout strength and increased risk of interbody subsidence. ${ }^{1,19-23}$ Previously, osteoporosis was a contraindication for instrumented spinal fusion due to increased rates of failure, but advancements in cement augmentation and spinal fixation have changed this outlook. ${ }^{24}$ Multiple studies have shown the efficacy of PMMA augmentation in instrumented posterior spinal 
fusion. ${ }^{22,25,26} \mathrm{Kim}$ et $\mathrm{al}^{8}$ evaluated anterior cement augmentation of ALIF in osteoporotic patients, but they did so in patients receiving simultaneous instrumented posterior spine fusion because of the theoretically superior strength and fusion rates of circumferential stabilization. In a cadaveric biomechanical analysis, however, Choi et $\mathrm{al}^{13}$ demonstrated that an anterior stand-alone cage compared with circumferential fixation provides sufficient stability and better simulates anterior-posterior load distribution of a normal intact spine, ultimately leading to significantly less adjacent segment stress and facet joint deterioration. The all-anterior approach described in this report allows for decreased operative times, decreased risk of neurologic damage, and retention of intact posterior muscular and ligamentous support structures. ${ }^{7,9}$ As compared with percutaneous pedicle screw placement, the allanterior lumbar approach without posterior fixation also leads to reduction in radiation exposure and avoids damage to the cranial facet joints that can lead to worsening of postoperative pain. ${ }^{10}$ Vertebroplasty has long been utilized in the treatment of osteoporotic vertebral compression fractures to strengthen the vertebral body, but this procedure has significant risks associated with cement extravasation. ${ }^{27,28}$ Leakage of the cement, either by way of migration across fractured vertebral body cortex or into external venous plexus, can cause severe complications, including neural compression and cement embolus, respectively. ${ }^{29,30}$ The use of effective prophylactic vertebroplasty in the form of cement augmentation, however, is associated with a far lower complication rate than that for osteoporotic vertebral compression fracture because the vertebral bodies remain intact., ${ }^{9,31,32}$ The use of PMMA cement augmentation has also been shown to improve initial screw fixation as well as drastically increase pullout strength..$^{20,25,33}$ Furthermore, the use of prophylactic anterior cement augmentation has been shown to decrease cage subsidence following ALIF and PSF in osteoporotic patients. ${ }^{8}$

Cement augmentation does have associated risks that are particularly prone to occur in osteoporotic patients. Reports of failed cement-augmented instrumentation exist, and potential consequences can be more drastic than nonaugmented screws, as the intact cement-screw complex can be displaced through compromised bone. ${ }^{34}$ These reports warn surgeons against becoming too reliant on cement augmentation, as the underlying disease must be evaluated for operative risk. Vertebroplasty has also been implicated in higher rates of adjacent segment degeneration because improving the structural integrity of an osteoporotic vertebra at one level increases the force placed on and decreases the load to failure of adjacent vertebrae. ${ }^{26,35-37}$ Prophylactic cement augmentation, however, has been shown through both biomechanical analysis and clinical studies to confer no additional risk of adjacent segment degeneration. 8,38

In conclusion, stand-alone ALIF with anterior cement augmentation without posterior supplemental fixation is a potential surgical treatment option for patients with isthmic spondylolisthesis and comorbid osteoporosis or osteopenia. The technique provides adequate fixation while avoiding complications associated with posterior pedicle screw fixation.

\section{REFERENCES}

1. Dodwad SNM, Khan SN. Surgical stabilization of the spine in the osteoporotic patient. Orthop Clin $N \mathrm{Am}$. 2013;44(2):243-249. http://doi.org/10.1010/j.ocl.2013.01.008.

2. Jacobs WCH, Vreeling A, De Kleuver M. Fusion for low-grade adult isthmic spondylolisthesis: a systematic review of the literature. Eur Spine J. 2006;15(4):391-402.

3. Wang SJ, Han YC, Liu XM, et al. Fusion techniques for adult isthmic spondylolisthesis: a systematic review. Arch Orthop Trauma Surg. 2014;134(6):777-784. https://doi.org/10. 1007/s00402-014-1985-9.

4. Cho W, Sokolowski MJ, Mehbod AA, et al. MRI measurement of neuroforaminal dimension at the index and supradjacent levels after anterior lumbar interbody fusion: a prospective study. Clin Orthop Surg. 2013;5(1):49-54. https:// doi.org/10.4055/cios.2013.5.1.49.

5. Russell RG, Espina B, Hulley P. Bone biology and the pathogenesis of osteoporosis. Curr Opin Rheumato. 2006;18(suppl 1):S-10.

6. Vaishya R, Chauhan M, Vaish A. Bone cement. J Clin Orthop Trauma. 2013;4(4):157-163.

7. Gerber M, Crawford NR, Chamberlain RH, Fifield MS, LeHuec JC, Dickman CA. Biomechanical assessment of anterior lumbar interbody fusion with an anterior lumbosacral fixation screw-plate: comparison to stand-alone anterior lumbar interbody fusion and anterior lumbar interbody fusion with pedicle screws in an unstable human cadaver model. Spine (Phila Pa 1976). 2006;31(7):762-768.

8. Kim KH, Lee SH, Lee DY, Shim CS, Maeng DH Anterior bone cement augmentation in anterior lumbar interbody fusion and percutaneous pedicle screw fixation in patients with osteoporosis. J Neurosurg Spine. 2010;12(5):525532. doi: $10.3171 / 2009$.

9. O'Brien JP, Holte DC. Simultaneous combined anterior and posterior fusion. A review of its concept and 10 years of refinement of the technique: a solution for the patient with severe back and leg pain. Eur Spine J. 1992;1(1):2-6. 
10. Patel RD, Graziano GP, Vanderhave KL, Patel AA, Gerling MC. Facet violation with the placement of percutaneous pedicle screws. Spine (Phila Pa 1976). 2011;36(26):E1749E1752. https://doi.org/10.1097/BRS.0b013e318221a800.

11. Christensen FB, Karlsmose B, Hansen ES, Bunger CE. Radiological and functional outcome after anterior lumbar interbody spinal fusion. Eur Spine J. 1996;5(5):293-298.

12. Kuslich SD, Danielson G, Dowdle JD, et al. Four-year follow-up results of lumbar spine arthrodesis using the Bagby and Kuslich lumbar fusion cage. Spine (Phila Pa 1976). 2000;25(20):2656-2662.

13. Choi KC, Ryu KS, Lee SH, Kim YH, Lee SL, Park CK. Biomechanical comparison of anterior lumbar interbody fusion: stand-alone interbody cage versus interbody cage with pedicle screw fixation - a finite element analysis. BMC Musculoskeletal Disord. 2013;14:220. https://doi.org/10.1186/14712474-14-220.

14. Nagahama $\mathrm{K}$, Kanayama M, Togawa D, Hashimoto $\mathrm{T}$, Minami A. Does alendronate disturb the healing process of posterior lumbar interbody fusion? A prospective randomized trial. J Neurosurg Spine. 2011;14(4):500-507. https://doi.org/10. 3171/2010.11.SPINE10245.

15. Anjarwalla NK, Morcom RK, Fraser RD. Supplementary stabilization with anterior lumbar intervertebral fusion-a radiologic review. Spine (Phila Pa 1976). 2006;31(11):1281-1287.

16. Strube P, Hoff E, Hartwig T, Perka CF, Gross C, Putzier M. Stand-alone anterior versus anteroposterior lumbar interbody single-level fusion after a mean follow-up of 41 months. J Spinal Disord Tech. 2011;10(7):469-473.

17. Ishihara H, Osada R, Kanamori M, Kawaguchi Y, Ohmori K, Kimura T. Minimum 10-year follow-up study of anterior lumbar interbody fusion for isthmic spondylolisthesis. J Spinal Disord. 2001;14(2):91-99.

18. Riouallon G, Lachaniette CHF, Poignard A, Allain J. Outcomes of anterior lumbar interbody fusion in low-grade isthmic spondylolisthesis in adults: a continuous series of 65 cases with an average follow-up of 6.6 years. Orthop Traumatol Surg Res. 2013;99(2):155-161. https://doi.org/10.1016/j.otsr. 2012.12.009.

19. Cook SD, Salkeld SL, Stanley T, Faciane A, Miller SD. Biomechanical study of pedicle screw fixation in severely osteoporotic bone. Spine J. 2004;4(4):402-408.

20. Burval DJ, McLain RF, Milks R, Inceoglu S. Primary pedicle screw augmentation in osteoporotic lumbar vertebrae: biomechanical analysis of pedicle fixation strength. Spine (Phila Pa 1976). 2007;32(10):1077-1083.

21. Halvorson TL, Kelley LA, Thomas KA, Whitecloud TS III, Cook SD. Effects of bone mineral density on pedicle screw fixation. Spine (Phila Pa 1976). 1994;19(21):2415-2420.

22. Hashemi A, Bednar D, Ziada S. Pullout strength of pedicle screws augmented with particulate calcium phosphate: an experimental study. Spine J. 2009;9(5):404-410. https://doi. org/10.1016/j.spinee.2008.07.001.

23. Ryken TC, Goel VK, Clausen JD, Traynelis VC. Assessment of unicortical and bicortical fixation in a quasistatic cadaveric model: role of bone mineral density and screw torque. Spine (Phila Pa 1976). 1995;20(17):1861-1867.

24. Mobbs RJ, Loganathan A, Yeung V, Rao PJ. Indications for anterior lumbar interbody fusion. Orthop Surg. 2013;5(3):153-163. https://doi.org/10.1111/os.12048.

25. Frankle BM, D'Agostino S, Wang C. A biomechanical cadaveric analysis of polymethylmethacrylate-augmented pedicle screw fixation. J Neurosurg Spine. 2007;7(1):47-53.

26. Polikeit A, Nolte LP, Ferguson SJ. The effect of cement augmentation on the load transfer in an osteoporotic functional spinal unit: finite-element analysis. Spine (Phila Pa 1976). 2003;28(10):991-996.

27. Boonen S, Wahl DA, Nauroy L, et al. Balloon kyphoplasty and vertebroplasty in the management of vertebral compression fractures. Osteoporos Int. 2011;22(12):2915-2934. https://doi.org/10.1007/s00198-011-1639-5.

28. Hadjipavlou AG, Tzermiadianos MN, Katonis PG, Szpalski M. Percutaneous vertebroplasty and balloon kyphoplasty for the treatment of osteoporotic vertebral compression fractures and osteolytic tumors. J Bone Joint Surg Br. 2005;87(12):15951604. https://doi.org/10.1302/0301-620X.87B12.16074.

29. Ha KY, Kim YH, Chang DG, Son IN, Kim KW, Kim SE. Causes of late revision surgery after bone cement augmentation in osteoporotic vertebral compression fractures. Asian Spine J. 2013;7(4):294-300. https://doi.org/10.4184/asj. 2013.7.4.294.

30. Sidhu GS, Kepler CK, Savage KE, Eachus B, Albert TJ, Vaccaro AR. Neurological deficit due to cement extravasation following vertebral augmentation procedure. J Neurosurg Spine. 2013;19(1):61-70. https://doi.org/10.3171/2013.4. SPINE12978.

31. Furtado N, Oakland RJ, Wilcox RK, Hall RM. A biomechanical investigation of vertebroplasty in osteoporotic compression fractures and in prophylactic vertebral reinforcement. Spine (Phila Pa 1976). 2007;32(17):E480-E487.

32. Sun K, Liebschner MA. Biomechanics of prophylactic vertebral reinforcement. Spine (Phila Pa 1976). 2004;29(13):1428 1435 .

33. Sawakami K, Yamazaki A, Ishikawa $\mathrm{S}$, Ito $\mathrm{T}$, Watanabe K, Endo N. Polymethylmethacrylate augmentation of pedicle screws increases the initial fixation in osteoporotic spine patients. J Spinal Disord Tech. 2012;25(2):E28-E35. https://doi.org/10.1097/BSD.0b013e318228bbed.

34. Mesfin A, Komanski CB, Khanna AJ. Failure of cement-augmented pedicle screws in the osteoporotic spine: a case report. Geriatr Orthop Surg Rehabil. 2013;4(3):84-88. https://doi.org/10.1177/2151458513500787.

35. Kim SH, Kang HS, Choi JA, Ahn JM. Risk factors of new compression fractures in adjacent vertebrae after percutaneous vertebroplasty. Acta Radiol. 2004;45(4):440-445.

36. Trout AT, Kallmes DF, Kaufmann TJ. New fractures after vertebroplasty: adjacent factures occur significantly sooner. AJNR Am J Neuroradiol. 2006;27(1):217-223.

37. Uppin AA, Hirsch JA, Cemtenera LV, Pfiefer BA, Pazianos AG, Choi IS. Occurrence of new vertebral body fracture after percutaneous vertebroplasty in patients with osteoporosis. Radiology. 2003;226(1):119-124. https://doi.org/ 10.1148/radiol.2261011911.

38. Oakland RJ, Furtado NR, Wilcox RK, Timothy J, Hall RM. The biomechanical effectiveness of prophylactic vertebroplasty: a dynamic cadaveric study. $J$ Neurosurg Spine. 2008;8(5):442-449. https://doi.org/10.3171/SPI/2008/8/5/442.

Disclosures and COI: No funds were received in support of this work. The authors report no conflict of interest concerning the materials or 
methods used in this study or the findings specified in this paper. This study was approved by the Institutional Review Board of George Washington University Hospital in Washington, DC.

Corresponding Author: Joseph R. O'Brien, MD, MPH, OrthoBethesda, 10215 Fernwood Road, Physician Suite \#506, Bethesda, MD 20817.
Phone: (301) 530-1010; Fax: (301) 897-8597; Email: obrienjr@gmail.com.

Published 15 August 2018

This manuscript is generously published free of charge by ISASS, the International Society for the Advancement of Spine Surgery. Copyright (C) 2018 ISASS. To see more or order reprints or permissions, see http://ijssurgery.com. 